\title{
Behavior of porous silicon crystallite size analized by Raman spectroscopy and phonon confinement model
}

\section{Comportamento do tamanho do cristalito no silício poroso analizado por espectroscopia Raman e o modelo de confinamento de fônons}

Miguel Angelo do Amaral Junior ${ }^{1}$, Neidenêi Gomes Ferreira ${ }^{1}$, Antonio Fernando Beloto ${ }^{1}$, Maurício Ribeiro Baldan ${ }^{1}$

\section{ABSTRACT}

Porous silicon samples were obtained by electrochemical process in a solution containing HF-Ethanol. The samples were prepared varying etching time and current density. Using the phonon confinement model was estimated the crystallite size on the porous layer through the best fit of the Raman spectrum of first order. The experimental and theoretical points were better adjusted in order to obtain more accurate results in relation to previous works. For the samples varying in the anodization time and constant current density the crystallite size had a small oscillation but remains practically constant as a function of the anodization time. Varying current density and keeping constant the anodization time was observed an increase in the crystallite size as a function current density.

Keywords: Microporous materials; Phonon; Defects; Nanostructures; Raman spectroscopy

\section{RESUMO}

As amostras de silício poroso foram obtidas por processo eletroquímico em uma solução contendo HF-Etanol. As amostras foram preparadas variando o tempo de anodização e a densidade de corrente. Utilizando o modelo de confinamento de fônons foi estimado o tamanho do cristalito sobre a camada porosa através do melhor ajuste do espectro Raman de primeira ordem. Os pontos experimentais e teóricos foram melhores ajustados a fim de obter resultados mais precisos em relação aos trabalhos anteriores. Para as amostras com variação no tempo de anodização e densidade de corrente constante, o tamanho do cristalito apresenta uma pequena oscilação, mas se mantém praticamente constante em função do tempo de anodização. Variando a densidade de corrente e fixando o tempo de anodização foi observado um aumento no tamanho do cristalito em função da densidade de corrente.

Palavras-chave: Materiais microporosos; Fônons; Defeitos; Nanoestruturas; Espectroscopia Raman.

'Instituto Nacional de Pesquisas Espaciais - São José dos Campos (SP) - Brazil.

Correspondent author: Miguel Angelo do Amaral Junior - Instituto Nacional de Pesquisas Espaciais - Avenida dos Astronautas, 1758 - Jardim da

Granja - CEP 12.227-010 - São José dos Campos (SP) - Brazil

E-mail: miguel.amaral@las.inpe.br

Received: 23/02/2015 Aproved: 23/03/2015 


\section{INTRODUCTION}

Porous silicon (PS) is considered a structured material formed by silicon crystallites of micro/nanometric dimensions that are randomly distributed on the porous surface. Since the discovery of its room temperature luminescence ${ }^{(1-3)}$ became one of the most researched materials for optoelectronic device application. The porosity is an intrinsic physical characteristic of this material, which is determined by the formation process conditions, and is directly related with the photoluminescence spectrum generated, but it does not give microscopic information on the morphology of the PS layers, the pore sizes and shapes, the crystallite size and topological distribution. Micro-Raman spectroscopy can give indirect information on the microstructure of PS. When associated with the phonon confinement model ${ }^{(4,5)}$ the crystallite size can be estimated on the porous layer and it is directly related with the photoluminescence generated that is extended from 540 to $850 \mathrm{~nm}$. The origin of this phenomenon is mainly attributed to quantum confinement effects in nanometer size silicon crystallite $^{(6,7)}$. The model assumes that the carriers are confined in the silicon nanocrystals and the increase of its band gap occurs with the reduction of crystallites size, allowing direct transitions due to break of the selection rules.

Electrochemical etching is widely used for producing PS on monocrystalline silicon, resulting in more homogeneous layers when compared with other techniques because of the photocurrent control and consequently the attack rate. In this work, two sets of porous silicon were prepared: one fixing the electrochemical attack time varying the current density and the other fixing the current density varying the electrochemical attack time. Structural analysis of the porous silicon samples was performed taking into consideration the best fit of the Raman spectrum of first order from 300 to $600 \mathrm{~cm}^{-1}$. The crystallite size was calculated using the phonon confinement model proposed by Richter in $1981^{(8)}$ and the Gaussian sum related to the amorphous part of the porous silicon. The equation is:

$$
\begin{aligned}
& I(w) \cong A \int \frac{4 \text { л. } q^{2} \cdot\left(e^{-q^{2} L / 4}\right) d q}{\left(w-\left(w_{\mathrm{o}}-120\left(\frac{q a_{\mathrm{o}}}{2 \pi}\right)^{2}\right)^{2}+\left(\frac{\mathrm{I}}{2}\right)\right.}+ \\
& \frac{B}{\Gamma_{\mathrm{a}}\left(\sqrt{\frac{\pi}{2}}\right)} e^{\frac{-2\left(w-w_{\mathrm{a}}\right)}{\Gamma_{\mathrm{a}}^{2}}}
\end{aligned}
$$

Where $w_{\mathrm{o}}$ peak position of Raman specter and $q$ is the wave vector. The $\Gamma$ is the FHWM of theory model and $\Gamma_{a}$ is the FHWM of Gaussian. The constants A and B used for normalization the intensity of the spectrum, $\mathrm{a}_{\mathrm{o}}$ is lattice parameter of silicon $(0.54 \mathrm{~nm})$ and $\mathrm{L}$ is the theoretical crystallite size, which is estimated.

A program with graphical interface was developed using the Python programming language along with Matplotlib and Numpy libraries, where the theoretical calculations for the size of the crystallites were performed.

\section{MATERIAL AND METHODS}

The crystallite size presented on the layer of porous silicon and its distribution depend on experimental parameters such as substrate type, doping level, acid concentration, etching time and current density. In this work samples of n-type monocrystalline silicon, with resistivity of $1-20 \Omega . \mathrm{cm}$ and crystallographic orientation (100) were used. A solution containing HF (48\%): deionized water: ethanol (95\%) in a volume ratio of (1:2:1) was used and the samples were prepared in a Teflon cell under lighting of $50 \mathrm{~W}$.

The first sample set was obtained varying only the electrochemical attack time and the second only the current density. The experimental conditions are displayed in Table 1.

Table 1: Changes in the condition of electrochemical attack

\begin{tabular}{c|c|c|c|c|c|c|c|c|c|c|c|c|}
\hline $\begin{array}{c}\text { Samples } \\
\text { set }\end{array}$ & \multicolumn{3}{|c|}{$\begin{array}{c}\text { Variation } \\
\text { of time attack }\end{array}$} & \multicolumn{6}{c|}{$\begin{array}{c}\text { Variation } \\
\text { of current density }\end{array}$} \\
\hline $\begin{array}{c}\text { Time attack } \\
\text { (min) }\end{array}$ & 5 & 10 & 15 & 20 & 30 & 20 & 20 & 20 & 20 & 20 & 20 & 20 \\
$\begin{array}{c}\text { Variation of } \\
\text { current } \\
\left(\mathrm{mA} / \mathrm{cm}^{2}\right)\end{array}$ & 75 & 75 & 75 & 75 & 75 & 15 & 30 & 45 & 60 & 75 & 90 & 105 \\
\hline
\end{tabular}

The Raman spectra were obtained at room temperature using the equipment Micro Raman Renishaw 2000 System. The investigation of the Raman spectrum was held in the center of the sample by varying the Raman shift from 300 to $600 \mathrm{~cm}^{-1}$. To improve data reliability, several measurements were performed in the same position for each sample to obtain an average and a standard deviation. Unlike other studies ${ }^{(9,10)}$ we seek to make the best fit of the experimental and theoretical points. Thus, after obtaining the Raman spectrum, we performed a "fit" to increase the number of points and find points closer to the peak of the Raman spectrum. A program was developed to perform the calculations and estimate the size of crystallites (Fig. 1). In Fig.1, the green dots correspond to the experimental points 'fitted', the blue dashed line is calculated by the equation of Richter model reported above and the orange dotted line is the Gaussian function. In the left graph are plotted the calculation of the phonon confinement model and the Gaussian separately, the right graph displays the sum of intensities.

\section{RESULTS AND DISCUSSION}

Figures 2 and 3 show the Raman spectrum with the model calculation for the samples obtained with porous silicon etching time and current density variation respectively. The green dots correspond to the experimental points and the blue line the fit using the equation of phonon confinement model.

The crystallite size varies with the conditions used to prepare the PS. According to Fig. 4, crystallites size followed a slight oscillatory behavior with a tendency to keep constant at around $11.11 \mathrm{~nm}$ as a function of etching time. Although 
the anodizing time influence the morphology of porous layer, showed does not significantly change the Raman spectrum of the sample set keeping all spectrum with similar profiles (see Fig. 2), so the settings using the model did not affect the crystallite size.

Other authors have also studied the time influence on the crystallites size arranged on the porous silicon. Abramof, P.G. et al. ${ }^{(11)}$, used chemical etching technique for obtaining porous silicon and the results showed that the crystallite size followed a decreasing behavior until 4 minutes of chemical attack and varying from 9 to $12.5 \mathrm{~nm}$. After this period was also reported an oscillatory behavior in the crystallite size. Jingmei Lu et al. ${ }^{(12)}$ reported that the attack time has a high influence on the porous layer morphology and structure, and noted that the crystallites arranged on the PS were strongly influenced and decreased with increasing etching time.
Figure 5 shows that the current density influences the crystallites size and they increased with current density, varying from 9 to $12 \mathrm{~nm}$. This sample set showed to have a more linear behavior for crystallite size. Varying the current density is more likely larger crystallite size, perhaps due to the fact that high etching time may cause electropolishing in the porous surface, thereby causing stagnation in the crystallite size.

Deb et al. ${ }^{(13)}$ reinforces these results, using the phonon confinement model with the spherical crystallites to SP obtained by electrochemical attack in similar conditions to this work. They observed that the crystallite size varies on the porous layer and are smaller, with $10 \mathrm{~nm}$, in the center of the samples and major, with $30 \mathrm{~nm}$, on the edges of the samples. These results are in close agreement with the results reported in this work.

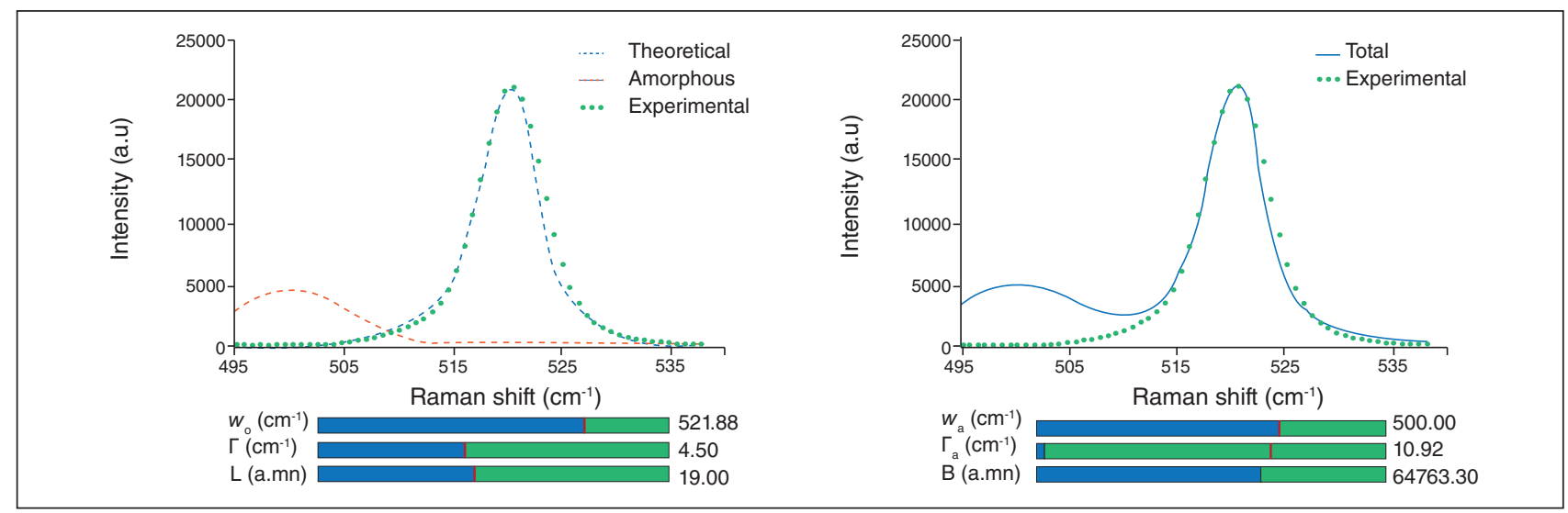

Figure 1: Comparison of experimental points and theoretical model for crystallites size calculations.

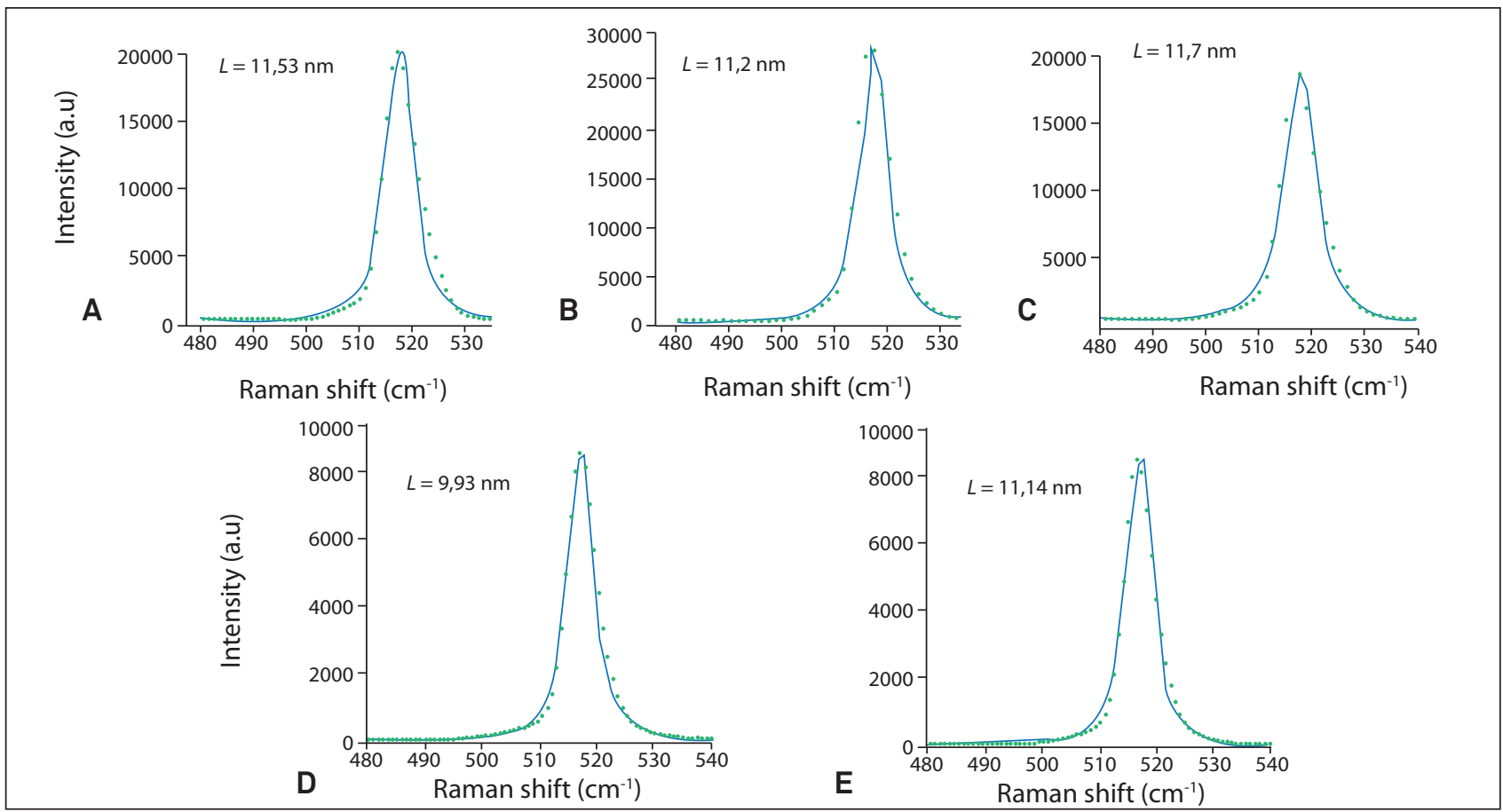

Figure 2: Calculation of Raman spectrum for the sample with time of (A) 5 (B) 10 (C) 15 (D) 20 and (E) 30 minutes attack. 

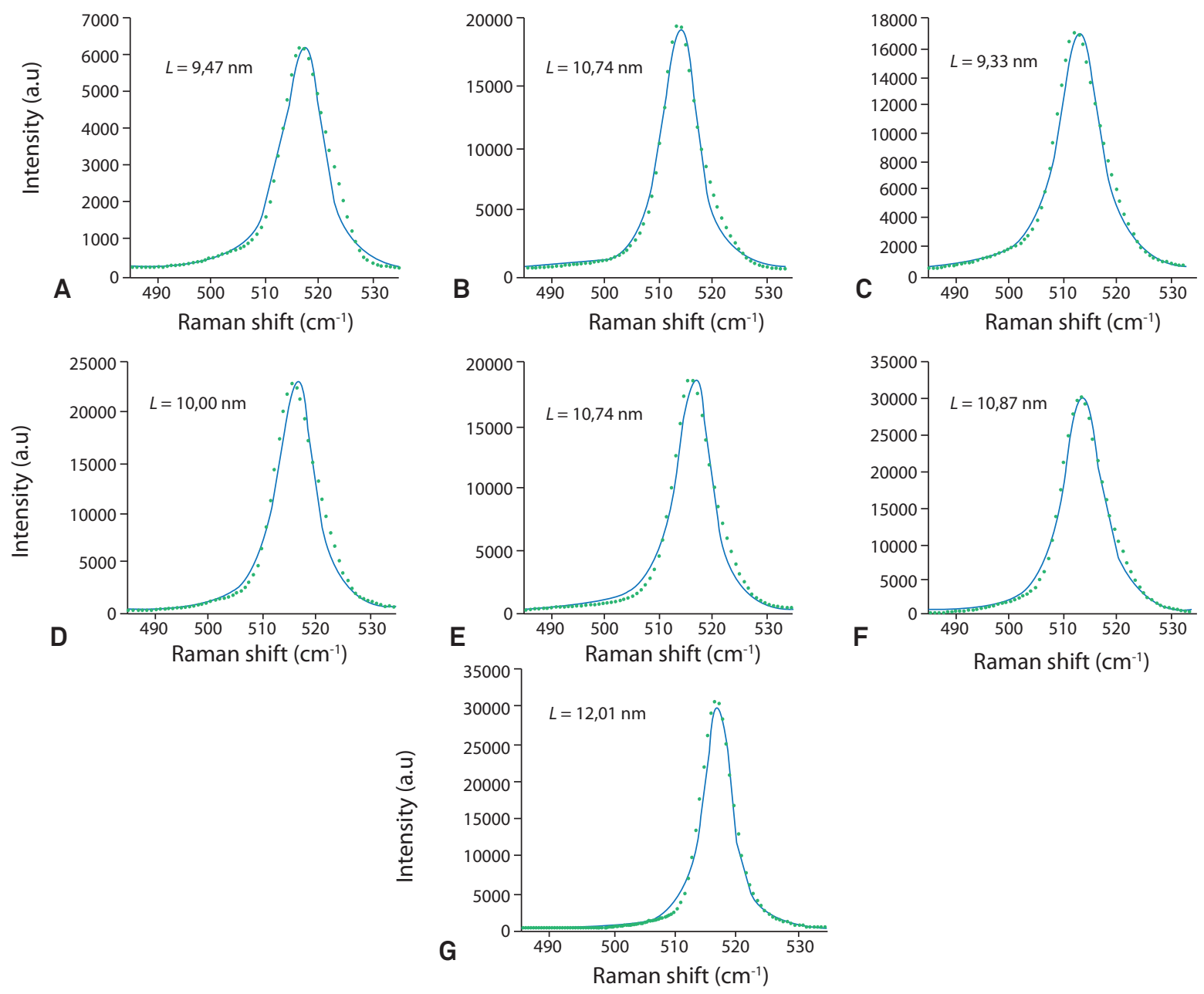

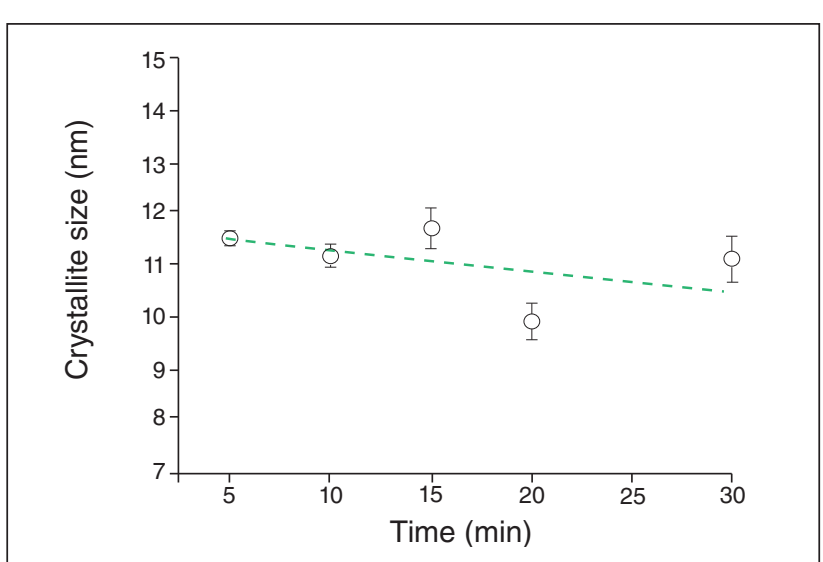

Figure 4: The crystallite size as a function of etching time.

\section{CONCLUSION}

This study was an improvement of the existing method for estimating the crystallite size and the behavior of its formation, showing that the analyses by Raman Spectroscopy and Phonon Confinement Model are very useful for understanding how nanostructures are arranged on the layer of porous silicon

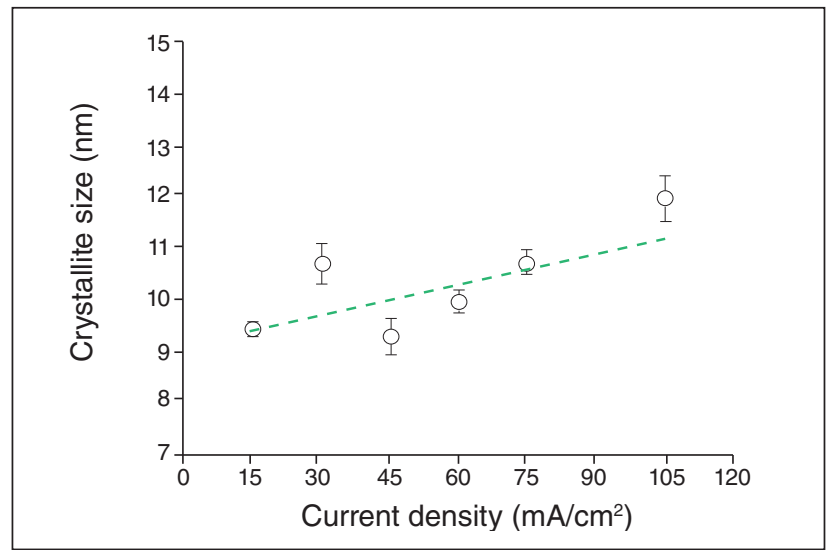

Figure 5: The crystallite size as a function of current density.

obtained by electrochemical attack. It showed clearly the variation of the crystallites size in the structure when the etching time and current density varies.

In the range of current density and electrochemical attack time chosen for this study, the crystallite sizes in the center of the samples remained in a range between 10 and $11.7 \mathrm{~nm}$, as a function 
of anodization time variation. By varying the current density was observed the size of the crystallites was between 9 and $12 \mathrm{~nm}$ and increased as a function of current density, showing a linear trend. The range of the crystallite size observed in other studies using the phonon confinement model proposed by Richter, are between 10 and $12 \mathrm{~nm}$, showing that the results of this study are in agreement with literature. Taking into consideration the suggestions of this study, the Raman spectrum with the phonon confinement model proved to be a rapid and useful method in determining the size of the crystallites on the PS layer.

\section{REFERENCES}

1. Cullis, A.G.; Canham, L.T.; Calcott, P.D.J.The structural and luminescence properties of porous silicon.Journal of Applied Physics, v.82, n.3, p.909-965, 1997.

2. Cullis, A.G.; Canham, L.T. Visible light emission due to quantum size effects in highly porous crystalline silicon.Nature, v.353, p.335, 1991.

3. Canham, L.T. Silicon quantum wire array fabrication by electrochemical and chemical dissolution of wafers.Applied Physics Letters, v.57, n.10, p.1046-1048, 1990.

4. Ristic, D.; Ivanda M.; Furic K. Application of the phonon confinement modelo $\mathrm{n}$ the optical phonon mode of silicone naoparticles.Journal of Molecular Structure, v.924-926, p.291293, 2009.
5. Grujic-brojcin, M.; Scepanovic, M.J.; Dohcevic-Mitrovic, Z.D.; Popovic, Z.V. Use of Phonon Confinement Model in Simulation of Raman Spectra of Nanostructured Materials. Acta PhysicaPolonica A, v. 116 (2009).

6. Abramo,P. G.; Beloto. A. F, Ueta. A. Y; Ferreira. N. G. X-ray investigation of nanostructured stain-etching porous silicon. Journal of Applied Physics, v.99, 2006.

7. Ambrosone, G.; Basa, D. K.; Coscia, U.; Passacantando, M. Evolution of structural and optical proprerties of nanostructured silicon carbon films deposited by plasma enhance chemical vapour deposition. Thin Solid Films.v.520, p.4875-4879, 2012.

8. Richter, H.; Wang, Z.P.; Ley, L.The one phonon Raman spectrum in microcrystalline silicon.Solid State Communications, v. 39, p. 625-629, 1981.

9. Ranber, S.; Prakash, S. Phenomenological description of phonon confinement in semiconductor nanocrystals.Surface Science, v.532-535, p.780-784, 2003.

10. Dossot, M.; Miska, P.; Rinnert, H.; Vergnat, M.; and Humbert, B. Phenomenological quantum confinement model for exactions and phonons applied to pholuminescence and Raman spectra of silicon nanocrystals.Physica Status Solidi (b), v.248, n.11, p.2724-2727, 2011.

11. Abramof, P. G.; Ferreira N. G.; Beloto, A. F.; Ueta A. Y., Investigation of nanostructured porous silicone by Raman spectroscopy and atomic force microscopy. v.338-340, p.139-142, 2004.

12. Jingmei L., Xuan C. Effect of Etching Time on Porous Silicon Formation.v.11,n.11, p.9-7,2008.

13. Deb, S. K.; Mathur, N.; Roy, P. A.; Banerjee; S. and Sardesai, A. Raman Scattering and photoluminescence study of porous silicon formed on n-type silicon.v.17, n.5, p.505-511, 1994. 